\title{
Liposarcoma cells with aldefluor and CD133 activity have a cancer stem cell potential
}

\author{
Eva W Stratford ${ }^{1 *}$, Russell Castro ${ }^{1}$, Anna Wennerstrøm, Ruth Holm², Else Munthe', Silje Lauvrak, \\ Bodil Bjerkehagen ${ }^{2}$ and Ola Myklebost ${ }^{1,3}$
}

\begin{abstract}
Aldehyde dehydrogenase (ALDH) has recently been shown to be a marker of cancer stem-like cells (CSCS) across tumour types. The primary goals of this study were to investigate whether ALDH is expressed in liposarcomas, and whether CSCS can be identified in the ALDH high subpopulation. We have demonstrated that ALDH is indeed expressed in 10 out of 10 liposarcoma patient samples. Using a liposarcoma xenograft model, we have identified a small population of cells with an inducible stem cell potential, expressing both ALDH and CD133 following culturing in stem cell medium. This potential CSC population, which makes up for 0, 1-1, 7\% of the cells, displayed increased selfrenewing abilities and increased tumourigenicity, giving tumours in vivo from as few as 100 injected cells.
\end{abstract}

\section{Introduction}

CSCs are described as a small population of tumour cells possessing stem-like properties, such as the ability to self-renew, as well as to differentiate into more mature cells that make up the bulk of the tumour, which usually to some extent resembles normal tissue. These cells are also referred to as tumour initiating [1].

The CSCs are in many aspects similar to normal stem cells, and are thought to arise either when normal stem cells gain oncogenic mutations, which confer enhanced proliferation and lack of homeostatic control mechanisms, or alternatively when a progenitor or differentiated cell acquires mutations conferring de-differentiation to a malignant stem-like cell [2]. Since the integrity of stem cells is of critical importance for the organism, several mechanisms that ensure the survival of stem cells have evolved. These mechanisms include enhanced activity of membrane pumps which remove toxic substances [3], and enhanced activity of enzymes such as aldehyde dehydrogenase (ALDH), which confer resistance to toxic agents $[4,5]$. ALDH1 was also found to be implicated in regulating the stem cell fate in hematopoietic stem cells (HSCs) [6]. Properties and functions of normal stem cells can also be employed to enrich CSCs. In this

\footnotetext{
* Correspondence: evaped@rr-research.no

'Cancer Stem Cell Innovation Centre and Department of Tumor Biology, Institute of Cancer Research, Oslo University Hospital, The Norwegian

Radium Hospital, PO Box 4953 Nydalen, Oslo, NO-0424, Norway

Full list of author information is available at the end of the article
}

respect, the Aldefluor assay, originally optimised to detect ALDH1 expression in HSCs [7] has been used to successfully enrich CSCs from breast cancer [8], leukemia [9], prostate cancer [10], colon cancer [11], bladder cancer [12] and liver cancer [13]. Because the Aldefluor substrate probably is not specific for this isoform [14], we refer only to ALDH-activity. ALDH-activity has also been associated with increased tumourigenicity in osteosarcoma [15]. Furthermore, several groups have reported that expression of ALDH is associated with high grade and poor prognosis in lung cancer [16], leukemia [9], ovarian cancer [17], breast cancer $[8,18]$, colon cancer [11], prostate cancer [10], bladder cancer [12] and head and neck cancer [19]. ALDH expression has also been correlated with resistance to chemotherapy $[19,20]$.

The surface molecule CD133, also known as AC133 and prominin-1, is expressed on normal stem cells [21] and on CSCs identified in a range of cancers [22], including cancer of the brain $[23,24]$, colon $[25,26]$, pancreas [27] and liver [28]. The majority of research concerning CD133 has been focused on epithelial cancers, but CD133 expressing-cells have also been observed in mesenchymal tumours. Recently, Tirino et al., reported that CD133 is expressed in all of 21 primary bone sarcoma samples analysed (0, 21-7, 85\%). Interestingly, the $\mathrm{CD}_{133^{+}}$cells displayed CSC characteristics, such as increased ability to generate tumours in vivo and form spheres in vitro. The $\mathrm{CD} 133^{+}$cells were also able to repopulate the culture with $\mathrm{CD} 133^{-}$cells, and were able 
to undergo differentiation [29]. Others have also reported that a subset of Ewing sarcoma primary tumours $[30,31]$ and synovial sarcoma primary tumours [32] harbour CD133-expressing cells. In addition, several osteosarcoma cell lines contain subpopulations of cells (typically 3-5\%), which are positive for CD133 [33].

Since the markers which are commonly used to isolate CSC populations do not uniquely identify CSCs, CSC enrichment can be improved by combining several markers. For instance, the enrichment of CSC populations from liver cancer cell lines using only CD133 was doubled when CD133 was used in combination with ALDH [13,28]. Similarly, Ginestier et al demonstrated that breast CSCs could be better enriched by combining Aldefluor with the markers CD $44^{+}$CD24- lin, originally used by Al-Hajj and co-workers [34].

In this article we confirm that ALDH is expressed in liposarcoma primary material. Using a liposarcoma xenograft model system we show that ALDH is also expressed in this system, and that the combined use of Aldefluor and CD133 enables enrichment of a small cell population by flow cytometry. The Aldefluor high CD133 high cells have CSC characteristics, such as increased ability to form spheroids in soft agar, and increased tumourigenicity in vivo.

\section{Materials and methods}

\section{Ethics statement}

The use of surplus patient material for cancer research is based on general written information and consent from the patients, combined with approval from the Regional Ethics Committee of Southern Norway for each project (Permit S-06133). All procedures involving animals were performed according to protocols approved by the National Animal Research Authority in compliance with the European Convention for the Protection of Vertebrates Used for Scientific Purposes (approval ID 1499, http://www.fdu.no).

\section{Immunohistochemical analyses of liposarcoma patient samples}

Ten formalin-fixed and paraffin-embedded liposarcoma patient samples were obtained from the Department of Pathology at Oslo University Hospital (The Norwegian Radium Hospital). More specifically, the samples included 3 well-differentiated liposarcomas (grade 1-2), 3 de-differentiated liposarcomas (grade 4), 2 myxoid and round cell liposarcomas (grade 3-4) and 2 pleomorphic liposarcomas (grade 4). Four $\mu \mathrm{m}$ thick sections were made and processed for immunohistochemistry using the Dako EnVision ${ }^{\mathrm{TM}}$ Flex+ System (K8012, Dako Corporation) and Dakoautostainer. Sections were deparaffinized and epitopes unmasked using PT-Link (Dako) and EnVision $^{\mathrm{TM}}$ Flex target retrieval solution, low $\mathrm{pH}$. After blocking endogenous peroxidase with $0.03 \%$ hydrogen peroxide $\left(\mathrm{H}_{2} \mathrm{O}_{2}\right)$ for 5 minutes, the sections were incubated with monoclonal mouse antibodies ALDH (1:3000, BD Transduction Laboratories $\left.{ }^{\mathrm{TM}}\right)$ and CD133/1 (AC133) (1:25, Miltenyi Biotec Inc.) over night at $4^{\circ} \mathrm{C}$. Subsequently, the slides were incubated with EnVision ${ }^{\mathrm{TM}}$ Flex+ Mouse linker (15 min) and EnVision ${ }^{\mathrm{TM}}$ Flex/HRP enzyme (30 min). Tissue was stained for 10 minutes with 3'3-diaminobenzidine tetrahydrochloride (DAB) and then counterstained with haematoxylin, dehydrated and mounted in Diatex. Normal liver and the $\mathrm{CaCO} 2$ cell line (American Type Culture Collection No. HTB37 (Rockville, MD)) have been included as positive controls for ALDH and CD133, respectively. Negative controls included replacement of monoclonal antibodies with mouse myeloma protein of the same subclass and concentration as monoclonal antibodies. The immunoreactivity was evaluated according to the number of positively stained tumour cells $(0=$ none; $1<10 \%$; $2=$ $10-50 \% ; 3>50 \%)$

\section{Xenograft cell culture}

The ATCC liposarcoma cell line SW872 (HTB92) (originally generated from a surgical specimen with histopathology of undifferentiated malignant liposarcoma.) was utilized to establish a xenograft in locally bred athymic NCR nu/nu mice (nude mice). The xenograft was then passaged to a new mouse before the tumour reached maximum $2 \mathrm{~cm}^{3}$. In order to extract cells from the xenografts, typically 6 - 8 tumors were minced in Hank's buffered saline solution (Invitrogen). The tissuepieces were then incubated in $5 \mathrm{U} / \mathrm{ml}$ collagenase 4 (Worthington's) in DMEM:F12 (Gibco) for 45 minutes to 1 hour at $37^{\circ} \mathrm{C}$. Cells were collected by passing the mixture through a $70 \mu \mathrm{m}$ filter. The cells were subsequently maintained in either standard RPMI (Lonza) containing $10 \%$ fetal bovine serum (PAA laboratories Gmbh), $1 \times$ glutamax (Gibco) and $1 \mu \mathrm{g} / \mathrm{ml}$ penicillin/ streptomycin (Lonza) or in stem cell (SC)-medium (70\% mouse embryonic fibroblast conditioned medium (R\&D systems) mixed with $30 \%$ of human embryonic stem cell medium (containing 20\% "knock-out" serum replacement (Invitrogen), 1\% non essential amino acids (Gibco), 4 ng/ml bFGF (Invitrogen), 0, 1 mM $\beta$-mercaptoethanol (Sigma), $1 \times$ glutamax (Gibco) in DMEM:F12 $($ Gibco $))$ ). The cells were maintained in culture for 10 14 days before analyses were performed. Adherent cells were dissociated when sub-confluent using TrypLE (Invitrogen).

Phenotypic analysis and cell sorting using flow cytometry Spheroid-shaped aggregates were dissociated by $45 \mathrm{~min}$ utes incubation in TrypLE (Invitrogen) at $37^{\circ} \mathrm{C}$. Adherent cells were detached by a shorter incubation in 
TrypLE. Aldefluor staining (Stem Cell Technology) was performed at the concentration of $1 \times 10^{6} \mathrm{cells} / \mathrm{ml}$ Aldefluor assay buffer, according to the protocol recommended by the manufacturer. On all occasions the monoclonal mouse antibody TRA-1-85-APC (1:20, R\&D systems), which recognizes an epitope found on all human cells, was included. On some occasions the cells were subsequently labeled with one of the following monoclonal mouse antibodies CD44-PE (1:10), CD90-PE (1:20), CD73-PE (1:10) (All from BD Pharmingen), CD105-PE (1:20, eBioscience), CD133/2(293C)-PE (1:10, Miltenyie Biotec. Inc), STRO-1-PE (1:20, Santa Cruz Biotec) or fibroblast growth factor receptor (FGFR)1 (M19B2) (1:100, Abcam). Cells stained with FGFR1 antibody were subsequently labeled with Alexa Fluor 647 donkey anti-mouse IgG $(\mathrm{H}+\mathrm{L})(1 \mu \mathrm{g} /$ million cells, Invitrogen-Molecular Probes). The cells were incubated on ice for 40 minutes. The cells were then washed and filtered through a $40 \mu \mathrm{m}$ filter, and subsequently analyzed or sorted by flow cytometry. Analyses were performed using a FACS ARIA-2 (Becton Dickenson). Viable singlets which were TRA-1-85 ${ }^{+}$were sorted into the following four fractions: Aldefluor ${ }^{\text {high }}$ CD $133^{\text {high }}$, Aldefluor ${ }^{\text {high }}$ CD $133^{\text {low }}$, Aldefluor ${ }^{\text {low }}$ CD $133^{\text {low }}$ and Aldefluor ${ }^{\text {low }}$ CD133 $3^{\text {high }}$. The flow cytometry sorted cells were subject to viability analysis by trypan blue staining, before subsequent experiments were performed.

\section{Spheroid assay in soft agar}

One thousand cells from each flow cytometry sorted subpopulation were plated in $0,3 \%$ soft agar (Difco) in $\mathrm{SC}$-medium in $35 \mathrm{~mm}$ non-adhesive dishes. Two hundred and fifty $\mu \mathrm{l}$ SC-medium was added once a week. Uniform spheroids of minimum $50 \mu \mathrm{m}$ were counted approximately four weeks post plating.

\section{Adipocytic differentiation and Oil red $\mathrm{O}$ staining}

Cells were grown in standard RPMI (Lonza) containing $10 \%$ fetal bovine serum (PAA laboratories Gmbh), 1× glutamax (Gibco) and $1 \mu \mathrm{g} / \mathrm{ml}$ penicillin/streptomycin (Lonza), supplemented with an adipocytic differentiation cocktail (50 $\mu \mathrm{M}$ Indomethacin, $1 \mu \mathrm{M}$ Dexamethason, 0, $5 \mathrm{mM}$ isobutyl-methyl-xanthine (IBMX)). Following 21 days in culture, the cells were fixed in $70 \%$ ethanol and subsequently stained in $0,3 \%$ oil red $\mathrm{O}$, and analyzed in a fluorescence microscope (Olympus IX81). Lipid droplets in mature adipocytes appeared red.

\section{In vivo tumourigenicity}

Serial dilutions (100 - 25000 cells) of each sorted subpopulation were injected subcutaneously into the flanks of locally bred athymic NCR nu/nu mice (nude mice). TRA-1- $85^{+}$(human specific epitope) cells were injected as unselected controls. The cells were diluted in a final volume of $100 \mu \mathrm{l}$ DMEM:F12 (Gibco). Viability of the injected cells was confirmed by trypan blue (Sigma) staining prior to injection.

\section{Results}

Aldehyde dehydrogenase is expressed in primary human liposarcomas

Immunohistochemical analyses of ALDH1 expression in liposarcoma patient samples confirmed that 10 out of 10 samples expressed ALDH1. More specifically, 8 out of 10 samples expressed ALDH1 in more than $50 \%$ of the tumour cells. One patient sample displayed ALDH1 expression in $10-50 \%$ of the tumour cells, and for one patient sample, less than $10 \%$ of the tumour cells were ALDH1 positive (Figure 1, Table 1). The samples represented a range of liposarcoma sub-types (well-differentiated, de-differentiated, myxoid/round celled and pleomorphic liposarcoma). We were not able to find any correlations between particular liposarcoma subtypes and the level of ALDH1 expression in this small and diverse panel.

\section{Aldehyde dehydrogenase is expressed in the liposarcoma xenograft SW872}

Having confirmed that ALDH1 is indeed expressed in human liposarcomas, we wanted to investigate whether liposarcoma ALDH-positive cells could be associated with CSC activity. We preferred to use a xenograft model, because the passing of the xenograft from mouse to mouse ensures that the growth conditions are physiological and that tumour initiating cells are present. Aldefluor analysis of cells extracted from the SW872 liposarcoma xenograft showed that the SW872

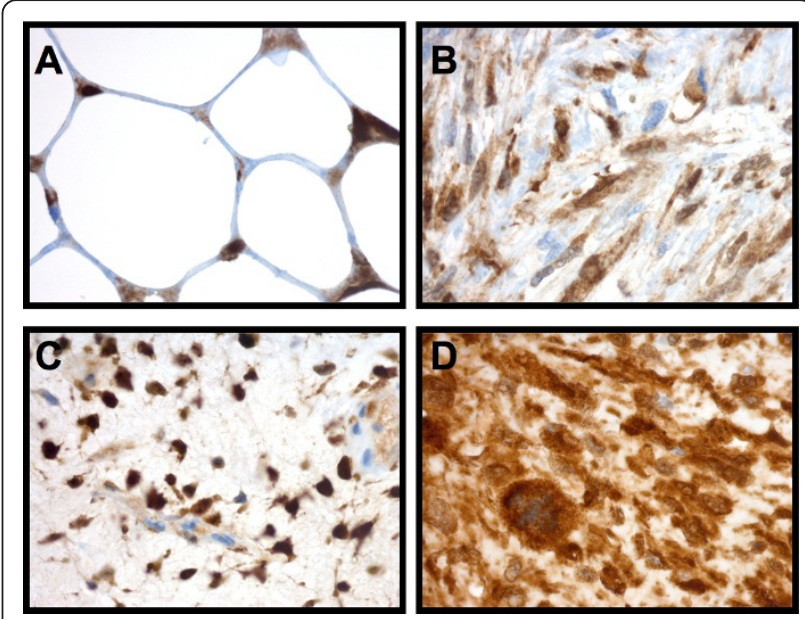

Figure 1 ALDH1 expression in liposarcoma patient samples ALDH1 was expressed in 10 out of 10 primary liposarcoma tumors analysed by immunohistochemsitry. (A) Well differentiated-, (B) Dedifferentiated-, (C) Myx/roundcell- and (D) Pleomorphic-liposarcoma. 
Table 1 CD133 and ALDH1 expression in liposarcoma patient samples.

\begin{tabular}{|c|c|c|c|c|c|c|c|}
\hline \multirow[t]{2}{*}{ Diagnosis } & \multirow[t]{2}{*}{ Tumour site } & \multirow[t]{2}{*}{ Age } & \multirow[t]{2}{*}{ Pre-treatment } & \multirow[t]{2}{*}{ Grade } & \multirow[t]{2}{*}{ CD133 } & \multicolumn{2}{|c|}{ ALDH1 } \\
\hline & & & & & & Cytoplasm & Nucleus \\
\hline Well-diff. & Retroperitoneal & 36 & No treatment & 1 & 0 & 3 & 3 \\
\hline Well-diff. & Retroperitoneal & 57 & No treatment & 2 & 0 & 3 & 3 \\
\hline Myx/roundcell & Thigh & 41 & No treatment & 3 & 0 & 3 & 3 \\
\hline Myx/roundcell & Thigh & 79 & Chemotherapy & 4 & 0 & 3 & 3 \\
\hline De-diff. & Thigh & 79 & No treatment & 4 & 0 & 3 & 3 \\
\hline De-diff. & Retroperitoneal & 60 & No treatment & 4 & 0 & 1 & 1 \\
\hline Well-diff. Comp * & Retroperitoneal & 64 & No treatment & & 0 & 3 & 3 \\
\hline De-diff. Comp* & Retroperitoneal & 64 & No treatment & 4 & 0 & 3 & 3 \\
\hline Pleomorphic & Truncus & 67 & No treatment & 4 & 0 & 3 & 3 \\
\hline Pleomorphic & Retroperitoneal & 58 & No treatment & 4 & 0 & 3 & 2 \\
\hline Well-diff. & Leg & 31 & No treatment & 1 & 0 & 2 & 2 \\
\hline
\end{tabular}

Ten liposarcomas diagnosed as well-differentiated (well-diff.), myxoid/roundcelled (myx/roundcell), de-differenitated (de-diff) or pleomorphic were included in the analyses. Tumour location, patient age, treatment prior to sample collection and tumour grade are also displayed. CD133 and ALDH1 expression was scored as follows: $0=$ negative, $1=$ less than $10 \%$ of the tumour cells scored positive, $2=10-50 \%$ of the rumour cells scored positive, $3=$ more than $50 \%$ of the tumour cells scored positive. *For one of the tumors, a de-differentiated and a well-differentiated component was analysed.

xenograft cells, like the liposarcoma patient samples, displayed ALDH activity (11\% of the cells were Aldefluor $^{\text {high }}$ : Figure 2B), making xenograft-derived SW872 cells a suitable model for further analyses of ALDHpositive cells.
Cellular growth pattern, morphology and expression of stem cell markers are affected by the culturing medium In order to maintain the extracted cells in a culturing medium best suited for enriching CSCs, we first investigated the effect of different culturing media on the

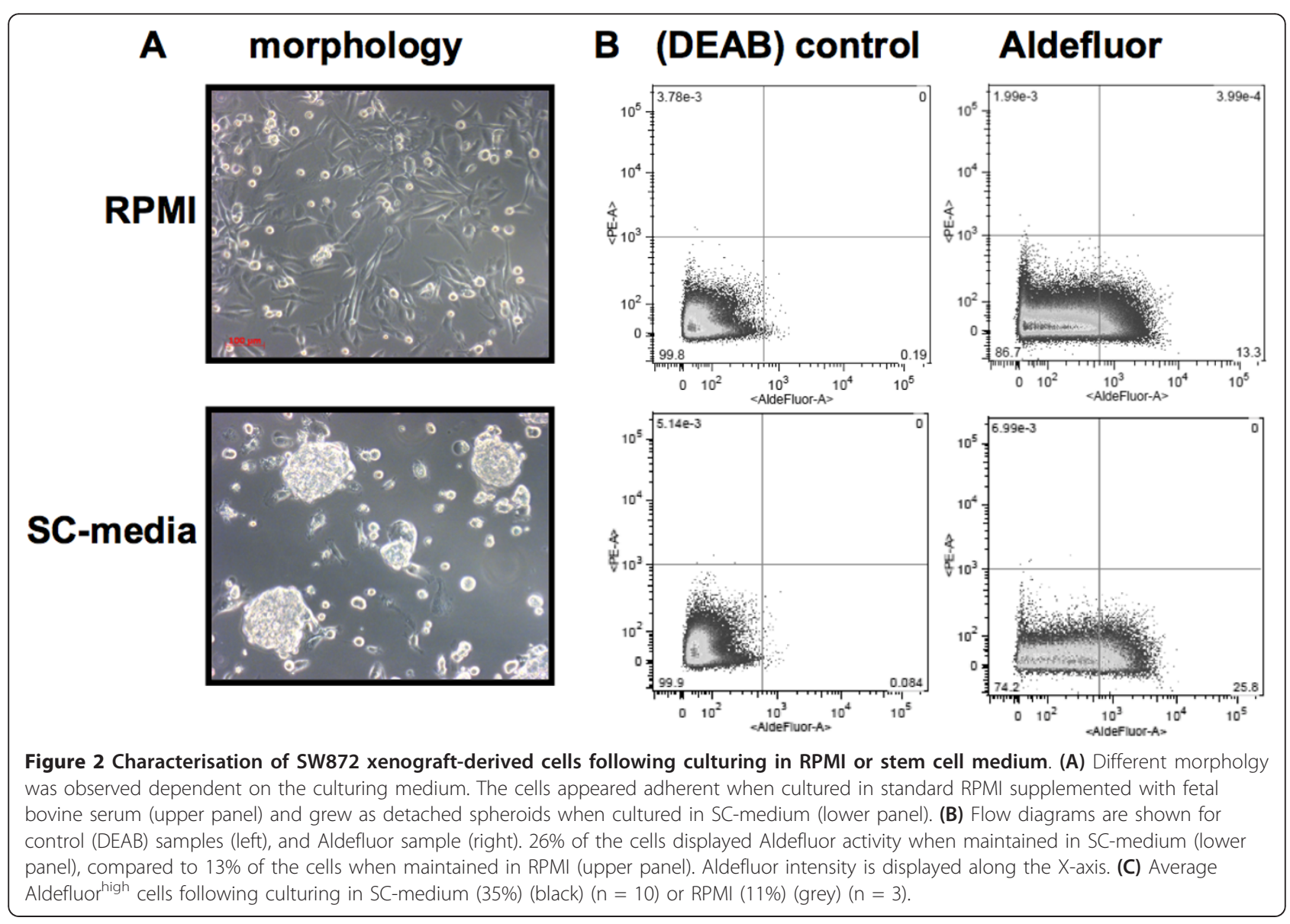


expression of ALDH and other stem cell markers. The extracted xenograft cells were therefore maintained for 10-14 days in either standard RPMI medium containing fetal bovine serum (RPMI) or stem cell medium (SCmedium) containing "knock-out" serum replacement, mouse embryonic fibroblast (MEF) conditioned medium and basic fibroblast growth factor (bFGF), commonly included in embryonic stem cell medium to prevent differentiation [35]. The cellular morphology was highly dependent on the culturing medium. Cells maintained in RPMI exhibited an adherent morphology and cells maintained in SC-medium attached to each other and grew as large aggregated spheroids in 3D suspension (Figure 2A). Cellular growth as spheroids in suspension has previously been associated with stem-ness and tumor initiating activity [36,37]. Interestingly, when the cells had been maintained in SC-medium, a larger percentage of the cells displayed ALDH activity (average $35 \%$ Aldefluor positive cells), compared to the average $11 \%$ observed when the cells were maintained in RPMI. The ALDH inhibitor diethylamino-benzaldehyde (DEAB) could block this activity (Figure 2B). Furthermore, when cells were initially incubated in RPMI for 6 days and then transferred into $\mathrm{SC}$-medium for the remaining period, the percentage of cells displaying Aldefluor activity increased (data not shown). These findings indicate that the cells comprise a degree of plasticity, and that cells which have the capacity to become more stem-like may do so in the presence of growth factors in the SC-medium. For instance, FGF signaling is implicated in regulation of self-renewal and differentiation. Since bFGF binds to and activates FGF Receptor 1 (FGFR1) [38], we decided to investigate FGFR1 membrane expression in SW872. Interestingly, we found that FGFR1 was highly expressed in the SW872 cell line. Furthermore, expression of FGFR1 was induced during culturing of xenograft-derived SW872 cells in SC-medium (86, 8\%) compared to culturing in RPMI (62, 8\%) (Table 2), indicating that activation of FGFR1 may result in expansion of CSCs. According to the CSC theory, the CSC population represent a small sub-population within the tumor [2]. In keeping with this theory, others have shown that a smaller, better enriched CSC population is isolated by flow cytometric cell sorting when combining the Aldefluor assay with antibody staining of CSC surface antigens $[8,13]$. Thus, we would expect the large Aldefluor ${ }^{\text {high }}$ cell population observed after culturing the cells in SC-medium to be heterogeneous, and the CSCs to represent a smaller population within the Aldefluor ${ }^{\text {high }}$ cell population.

In the case of liposarcoma, a likely cell of origin for the CSC would be a mesenchymal progenitor or stem cell (MSC). To our knowledge, no surface marker is known to uniquely identify MSCs, so we first tested the cell surface expression of the following markers, which are known to be expressed on MSCs: CD44, CD73, CD105, CD90 and STRO-1 [39,40]. We also included the stem cell and CSC marker CD133 in our screen [41]. In addition we performed phenotypic analyses of the original SW872 cell line (Table 2). With the aim to identify a small Aldefluor ${ }^{\text {high }}$ surface marker ${ }^{\text {high }}$ (doublepositive) cell population, we performed the Aldefluor

Table 2 Phenotypic analyses of SW872.

\begin{tabular}{|c|c|c|c|}
\hline SW872 & Xenograft-derived cells & Xenograft-derived cells & Cell line \\
\hline Surface marker & SC-medium & RPMI & RPMI \\
\hline FGFR-1 ${ }^{\text {high }}$ & 86,8 & 62,8 & 43,4 \\
\hline Aldefluourhigh $^{\text {high }}$ & 35,0 & 11,0 & 0,2 \\
\hline CD90 high & 93,3 & 89,4 & 41,6 \\
\hline CD44 high & 97,9 & 98,3 & 99,9 \\
\hline CD105 high & 97,5 & 95,6 & 82,1 \\
\hline STRO-1 ${ }^{\text {high }}$ & 0,5 & 0,7 & 0,3 \\
\hline CD73 high & 2,6 & 4,4 & 27,4 \\
\hline CD133 high & 0,6 & 0,3 & 0,3 \\
\hline Aldefluourh ${ }^{\text {high }}$ CD90 high & 41,9 & 5,5 & ND \\
\hline Aldefluour high CD44 high & 39,8 & 3,7 & ND \\
\hline Aldefluour ${ }^{\text {high }}$ CD105 high & 44,8 & 2,8 & $\mathrm{ND}$ \\
\hline Aldefluourhigh $_{\text {STRO-1 }}^{\text {high }}$ & 0,2 & 0,1 & ND \\
\hline Aldefluour $^{\text {high }}$ CD73 ${ }^{\text {high }}$ & 1,3 & 3,2 & ND \\
\hline Aldefluour ${ }^{\text {high }}$ CD133 $3^{\text {high }}$ & 0,1 & 0 & ND \\
\hline
\end{tabular}

The table displays the average percentages of cells scored as Aldelfuor ${ }^{\text {high }}$, surface marker ${ }^{\text {high }}$ or Aldelfuor ${ }^{\text {high }}$ surface $^{\text {marker }}{ }^{\text {high }}$ in the respective culturing $^{\text {he }}$ medium, as determined by flow cytometry (minimum two parallels were performed). The SW872 cell line was not subjected to co-staining as only $0,2 \%$ of the cells were scored as Aldefluor ${ }^{\text {high }}$. 
assay in combination with antibody staining against each surface marker. When testing Aldefluor in combination with CD90, CD44 or CD105 staining, we found that dual expression was observed in a small percentage of the cells following culturing in RPMI. The percentage of double-positive cells increased dramatically to approximately $40 \%$ due to an increasing number of cells expressing ALDH when the cells were maintained in SCmedium (Table 2). Next we tested Aldefluor in combination with STRO-1 or CD73 staining, and found that a relatively small percentage of cells were double-positive, independent of medium. Finally, we tested Aldefluor in combination with CD133 and found that no cells were double-positive when the cells were incubated in RPMI. However, interestingly we found that $0,1 \%$ of the cells displayed an Aldefluor ${ }^{\text {high }}$ CD $133^{\text {high }}$ phenotype when maintained in SC-medium. Because CSCs are expected to represent a small fraction of the tumour cells, using CD90, CD44 or CD105 in combination with Aldefluor would not be likely to result in sufficient enrichment of CSCs. On the contrary, CD73, STRO-1 and CD133 might be suitable as CSC-markers, since these markers, when combined with Aldefluor, identified a small population of SW872 xenograft-derived cells. The Aldefluorhigh $\mathrm{CD} 133^{\text {high }}$ phenotype was consistently observed in a small population $(0,1-1,7 \%, \mathrm{n}=9)$ of cells cultured in SC-medium. The Aldefluor ${ }^{\text {high }}$ CD133 ${ }^{\text {high }}$ subpopulation disappeared when cells were cultured in RPMI, indicating that the combined expression of these two stem cell markers had been induced by factors in the stem cell media. Subsequently, we were interested in evaluating whether cells with an Aldefluor ${ }^{\text {high }}$ CD $133^{\text {high }}$ phenotype comprised a CSC-potential. We therefore decided to perform further characterization of this subpopulation with respect to CSC abilities.

\section{Aldefluor ${ }^{\text {high }} \mathrm{CD} 133^{\text {high }}$ cells have an enhanced ability to form spheroids}

Using flow cytometry, we isolated 4 subpopulations based on ALDH and CD133 expression. In order to investigate the different cell population's stem-like ability to self-renew, we performed spheroid assays in soft agar. The Aldefluor ${ }^{\text {high }}$ CD133 ${ }^{\text {high }}$ cell population generated well-defined, round spheroids of approximately 50 $\mu \mathrm{m}$ in size (Figure 3A), at a frequency of up to 1 out of 4 cells. All the other three subpopulations generated spheroids at a significantly lower frequency (Figure 3B).

\section{Aldefluor $^{\text {high }} \mathrm{CD} 133^{\text {high }}$ cells have the ability to differentiate into adipocytes}

According to the theory, a CSC has the ability to both generate more CSCs through self-renewal, and to undergo partial differentiation generating heterogeneous cancer cells, which make up the bulk of the tumour.
Liposarcomas are in part composed of adipocytes and a potential liposarcoma CSC should therefore have the capacity to differentiate into adipocytes. When culturing the sorted cell populations in the presence of an adipocytic differentiation cocktail, we found that the Aldefluor $^{\text {high }}$ CD $133^{\text {high }}$ cells were able to differentiate into mature adipocytes more efficiently than the other sorted cell populations (Figure 4).

\section{Aldefluor $^{\text {high }} \mathrm{CD} 133^{\text {high }}$ cells form tumors more efficiently in vivo}

One of the hallmarks of CSCs is the increased ability to form tumors in vivo. Following flow cytometry, serial dilutions (100, 1000, 5000 and 25000 cells) of the four sorted subpopulations were injected into immunodeficient nude mice. The Aldefluor ${ }^{\text {high }} \mathrm{CD} 133^{\text {high }}$ cells produced tumors more efficiently in nude mice compared to the other sorted cell populations (Table 3). As few as 100 Aldefluor $^{\text {high }}$ CD133 ${ }^{\text {high }}$ cells were sufficient to generate tumors in $14 \%$ of the mice, whilst no tumors were formed when the other subpopulations were injected at this cell dilution. When injecting 5000 cells of the Aldefluor $^{\text {high }}$ CD $133^{\text {high }}$ subpopulation, the majority of the injections $(66 \%)$ resulted in tumour formation. We were unable to obtain sufficient number of cells to inject 25 000 Aldefluor ${ }^{\text {high }}$ CD133 ${ }^{\text {high }}$ cells.

\section{Discussion}

In this study, we initially chose to focus on Aldefluor as a CSC marker for several reasons. Firstly, the Aldefluor assay has been used to successfully isolate CSCs from several malignancies $[8-13,15]$. Secondly, we found ALDH1 a clinically relevant marker, identifying subpopulations of cancer cells in all liposarcoma patient samples analyzed. ALDH expression has proven a useful marker for cancers of several tissues [8-12,16-19,42]. Thirdly, the Aldefluor assay is less cytotoxic compared to other CSC isolation methods (e.g. side population assay), and since an intact cell membrane is required, only viable cells are isolated. Although the analyses of these phenotypes require separation of individual cells and short term in vitro culturing, we chose to use a xenograft-derived cell model to better mimic the 3D growth conditions and stroma interactions of in vivo human tumors. Furthermore, the continuous passaging of the xenograft ensured the presence of tumour-initiating cells. Moreover, in vitro conditions are not necessarily favorable for maintaining stem-ness, and we therefore compared the effects of two different culturing medium. Morphological observations and Aldefluor analyses of the SW872 xenograft-derived cells maintained in SC or RPMI medium indicated that the SC-medium was the more favourable for maintaining/inducing the CSC phenotype in vitro. The cells displayed an adherent 


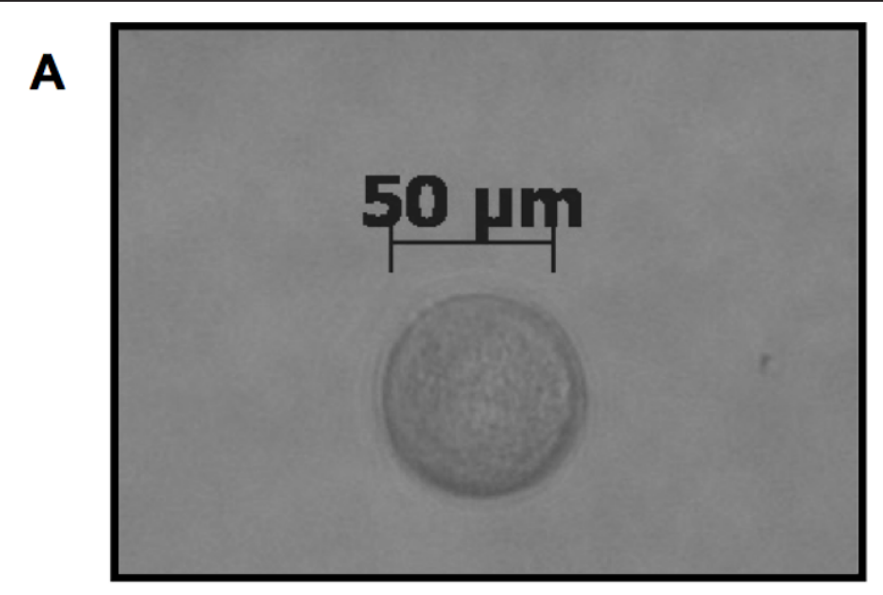

\section{B}

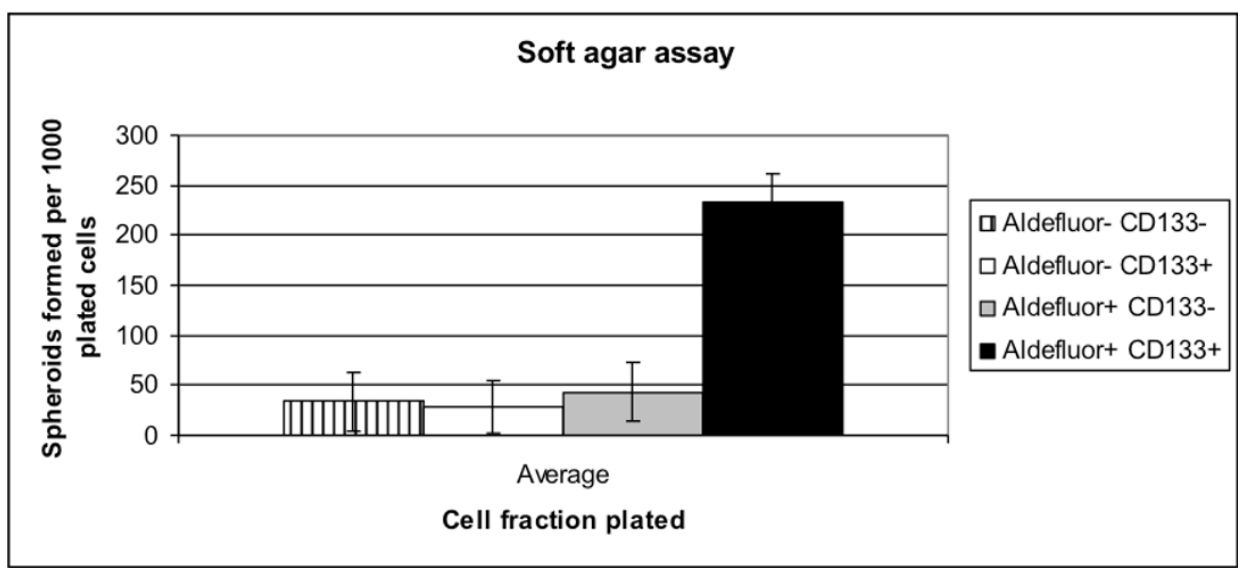

Figure 3 Aldefluour ${ }^{\text {high }}$ CD133 ${ }^{\text {high }}$ SW872 xenograft-derived cells form spheroids more effciently in soft agar. (A) Typical round-shaped spheroid of $50 \mu \mathrm{m}$ formed from single Aldefluour high $\mathrm{CD} 133^{\text {high }}$ cell. (B) Aldefluor high $\mathrm{CD} 133^{\text {high }}$ cells formed spheroids with a frequency of up to 1 out of 4 cells $(n=4)$.

cellular morphology when maintained in RPMI, while the cells grew as detached, round "spheroid"-aggregates when the cells were maintained in SC-medium, a growth-pattern that has been associated with stem-ness $[23,43]$. Furthermore, the fact that the percentage of cells which displayed ALDH activity was significantly higher when the cells were maintained in SC-medium also indicated that the SC-medium is favorable for enrichment of CSCs. Moreover, the observed increase in number of cells displaying high Aldefluor activity following a change of medium from RPMI to SC, indicates that a subpopulation of the bulk cells have a potential to become more "stem-like" in response to certain stimuli. It is likely that the 3D cell-cell contacts, as well as the mixture of growth factors in the SC-medium maintain and induce CSC self-renewal. Since a large percentage of the SW872 cells express FGFR1, and the percentage of cells expressing FGFR1 is further increased following culturing in SC-medium (containing
bFGF), it is possible that CSCs are enriched through FGFR activation.

A large percentage of the SW872 liposarcoma xenograft-derived cells were Aldefluor positive, making it unlikely that ALDH as a single marker could be used to identify a pure CSC population. Others have shown that the use of Aldefluor in combination with other stem cell markers improves the enrichment of CSCs $[8,13,42]$. A likely cell of origin for the sarcoma-CSC is an MSC-like stem or progenitor cell. However, since no markers are known to uniquely identify MSCs, we investigated a range of markers expressed on MSCs. We also included the stem cell and CSC marker CD133 [22-28,31]. Although several of the Aldefluor ${ }^{\text {high }}$ surface marker ${ }^{\text {high }}$ subpopulations identified in this screen might enrich for CSCs, the Aldefluor ${ }^{\text {high }}$ CD $133^{\text {high }}$ cells seemed particularly promising. This small subpopulation was only observed in the 3D spheroid culture (SC-medium), indicating that the phenotype was either selectively induced 


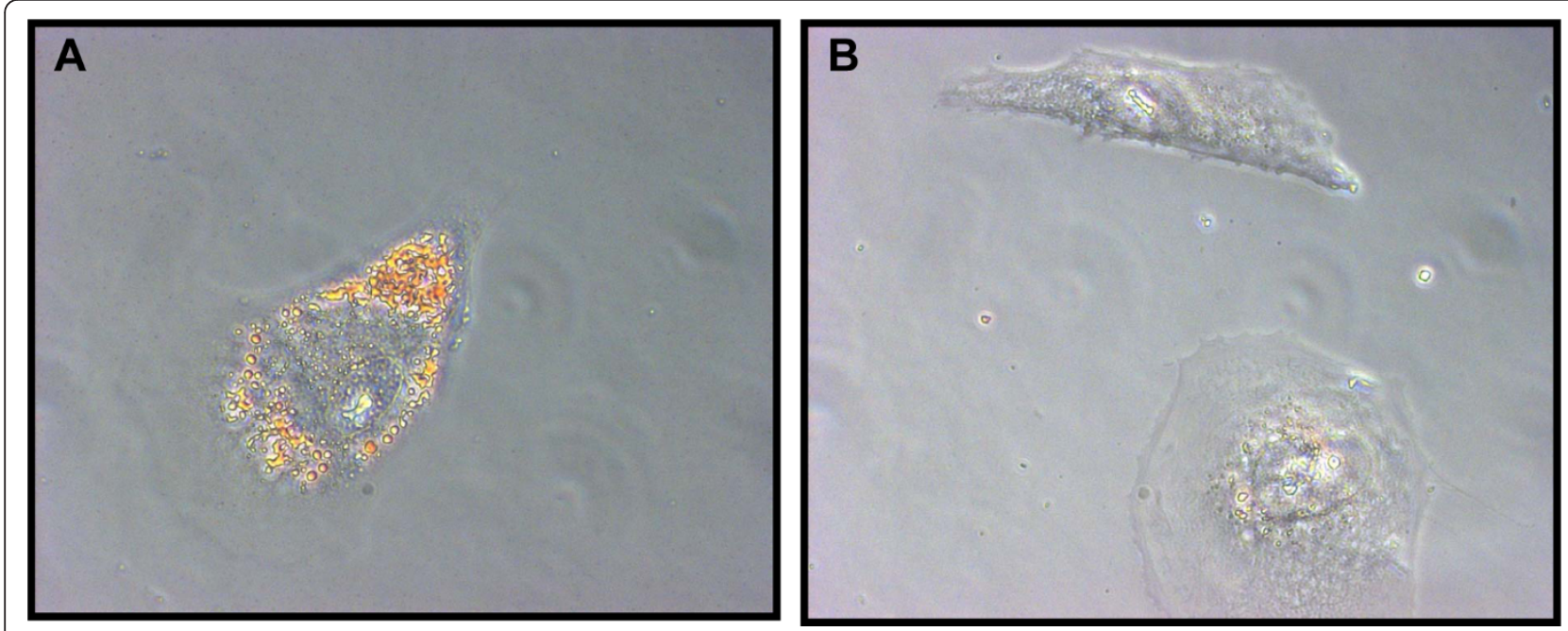

Figure 4 Aldefluour ${ }^{\text {high }}$ CD133 ${ }^{\text {high }}$ SW872 xenograft-derived cells differentiate into adipocytes. (A) Accumulation of lipid droplets indicative of mature adipocytes was observed following culturing of Aldefluour high CD133 ${ }^{\text {high }}$ sorted SW872 cells in medium supplemented with adipocytic differentiation cocktail (visualized by oil red O staining). (B) Aldefluour ${ }^{\text {high }}$ CD133 ${ }^{\text {high }}$ sorted SW872 cells did not differentiate as efficiently when maintained in standard RPMI medium.

by factors in the SC-medium, or was dependent on the growth pattern.

The functional analysis of the sorted subpopulations of SW872 cells demonstrated that the Aldefluor ${ }^{\text {high }}$ CD133 ${ }^{\text {high }}$ cells had a highly increased ability to form spheroids in soft agar, indicating that these cells have an increased ability to self-renew compared to the other sorted cell populations. Interestingly, the Aldefluor ${ }^{\text {high }}$ CD133 ${ }^{\text {high }}$ cells had higher capacity to differentiate into adipocytes. Whether the Aldefluor ${ }^{\text {high }} \mathrm{CD} 133^{\text {high }}$ cells have multi-lineage potential was not tested. However, since the Aldefluor ${ }^{\text {high }}$ CD133 ${ }^{\text {high }}$ CSC is likely to originate from a MSC, it would be interesting to investigate the ability of these cells to differentiate into other mesenchymal cell types, such as osteoblasts and chondrocytes. Our in vivo tumourigenicity assay showed that the Aldefluor ${ }^{\text {high }} \mathrm{CD} 133^{\text {high }}$ subpopulation overall generated tumors more efficiently compared to the other

Table 3 In vivo tumourigenicity of SW872 xenograftderived subpopulations.

\begin{tabular}{|c|c|c|c|c|}
\hline Cells injected & 25000 & 5000 & 1000 & 100 \\
\hline Aldefluor $^{\text {high }}$ CD133 $3^{\text {high }}$ & ND & $2 / 3$ & $4 / 14$ & $2 / 14$ \\
\hline Aldefluor high $C D 133^{\text {low }}$ & $2 / 12$ & $3 / 16$ & $2 / 14$ & $0 / 14$ \\
\hline Aldefluor ${ }^{\text {low }}$ CD133 high & $0 / 6$ & $1 / 16$ & $0 / 18$ & $0 / 16$ \\
\hline Aldefluor ${ }^{\text {low }} \mathrm{CD} 133^{\text {low }}$ & $2 / 14$ & $7 / 14$ & $7 / 18$ & $0 / 14$ \\
\hline TRA-1-85 (Control) & $2 / 12$ & $2 / 12$ & $8 / 16$ & $0 / 10$ \\
\hline
\end{tabular}

The table displays the total number of tumors formed, divided by the total number of injections performed. $100-25000$ cells of each group were injected subcutaneously into immunodeficient mice. Tumourigenicity was not determined (ND) for 25000 Aldefluor ${ }^{\text {high }}$ CD133 ${ }^{\text {high }}$ cells. TRA-1-85 ${ }^{+}$represent viable, single SW872 cells. The results are accumulated over three individual experiments. subpopulations when injected subcutaneously into nude mice, in particular at low cell numbers. However, at higher cell numbers tumors were also generated by some of the other subpopulations. Re-analyses of each isolated subpopulation was done by a second round of flow cytometry to determine the purity of the isolated fractions. As demonstrated in Figure 5, the Aldefluor ${ }^{\text {high }}$ CD133 ${ }^{\text {high }}$ subpopulation was only enriched to $33 \%$ purity, with a large percentage of tumour cells from the other subpopulations "diluting" the CSC population. The Aldefluor ${ }^{\text {high }} \mathrm{CD} 133^{\text {low }}$ flow sorted subpopulations was clearly "contaminated" with a few Aldefluor ${ }^{\text {high }}$ CD133 high cells, which likely contributed to tumour formation at high cell numbers. The purity of the flow sorting may be compromised by variability in expression and staining, but also by inherent "noise" in the flow sorter. The fact that the Aldefluor ${ }^{\text {high }} \mathrm{CD} 133^{\text {high }}$ cell population is only enriched also partly explains why tumors are not formed in all Aldefluor ${ }^{\text {high }}$ CD133 $33^{\text {high }}$ injections. Furthermore, when separating the cells into subpopulations, the CSCs may lack the support of cells that are required to make up a "niche" in vivo.

ALDH1 was expressed in all the liposarcoma patient samples analyzed by IHC. Although the level of expression varied from less than $10 \%$ of the tumor cells expressing ALDH1 to more than $50 \%$ of the tumor cells expressing ALDH1, we were not able to correlate the differences in level of expression with any particular factors; neither sub-type, tumor location, patient age or tumor grade. Furthermore, we were unable to confirm CD133 expression in the same panel (data not shown). There are several problems associated with CD133 

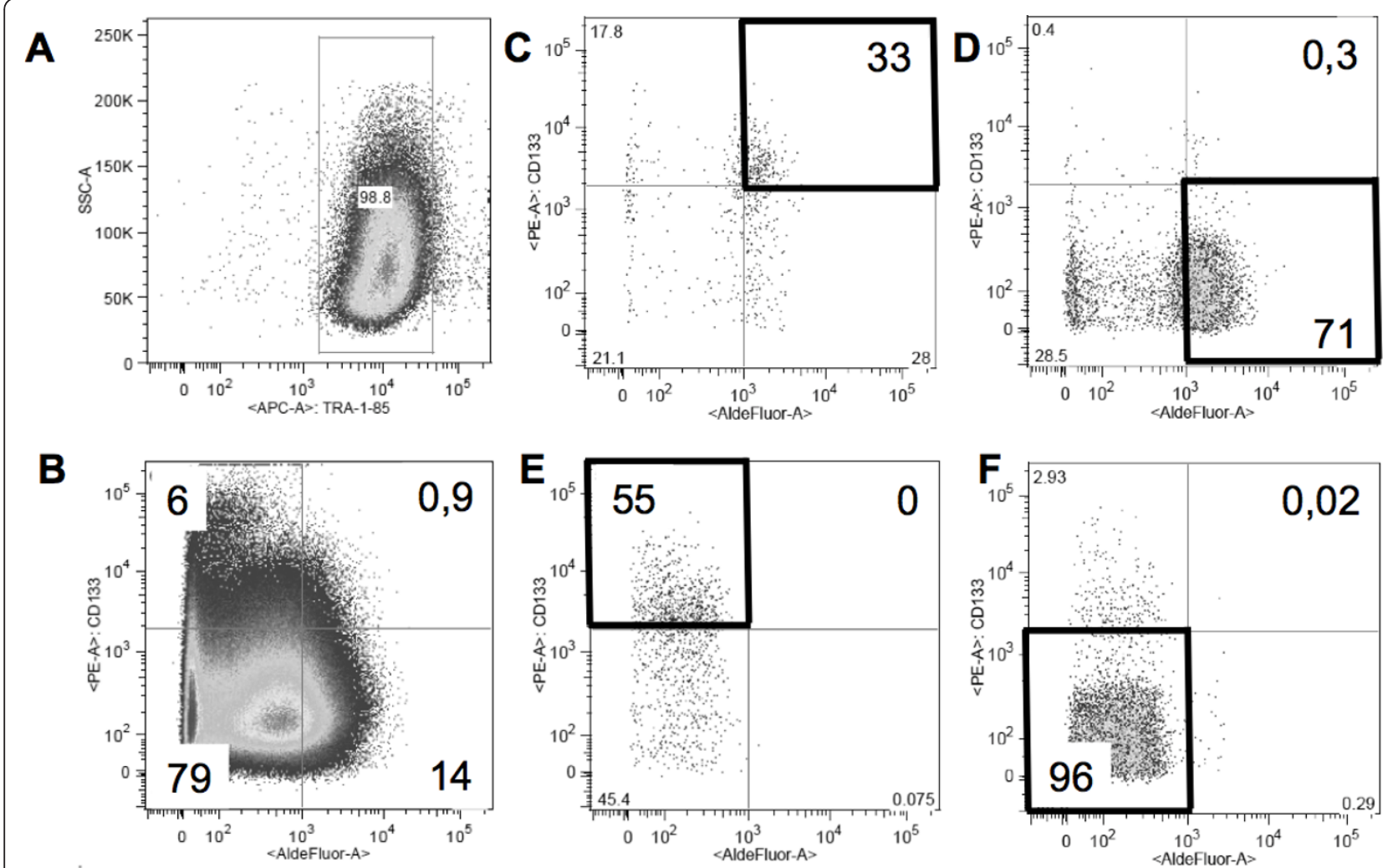

Figure 5 Flow cytometry and purity testing of sorted fractions. (A) Viable, single, human (TRA-1-85+) SW872 xenograft-derived cells (98, 8\%) were sorted on the basis of (B) Aldefluor (X-axis) and CD133 (Y-axis) activity. In this representative experiment the subpopulations in the culture

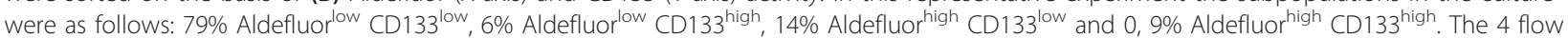

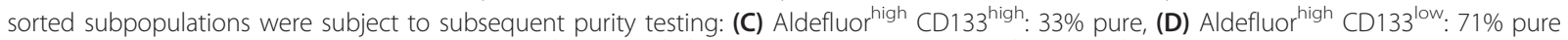
and containing 0, 3\% potential CSCS (E) Aldefluor ${ }^{\text {low }}$ CD133 ${ }^{\text {high }}: 55 \%$ pure and (F) Aldefluor ${ }^{\text {low }}$ CD133 $3^{\text {low: }}$ 96\% pure.

immunohistochemical expression analysis [41]. Several groups have reported that the antibodies binding CD133 detect only the glycosylated epitopes [44]. However, Kemper et al demonstrated that bacterially expressed CD133 or CD133 glycosylation mutants were indeed recognized by the CD133 antibody AC133 used here. Instead the authors concluded that the accessibility of the AC133 epitope varied [45]. Although we cannot confirm CD133 expression in our primary material, CD133 might still be present on the surface, but undetectable by the AC133 antibody due to epitope masking. Alternatively, expression of CD133 may only be present in very few cells or at a frequency below the detection level of immunohistochemistry. This is consistent with Suva et al and Tirino et al who both show that CD133 positive cells are extremely rare in sarcoma patient material $[29,31]$.

\section{Conclusion}

In conclusion, we have demonstrated that ALDH1 is expressed in liposarcoma patient samples, although we were unable to confirm CD133 expression in the same material. We have performed extensive phenotypic analyses of liposarcoma xenograft-derived cells using Aldefluor and surface markers, and as a result identified a CSC-like subpopulation of cells expressing both ALDH and CD133 when cultured as spheroids in SC-medium. Furthermore, we have demonstrated that this phenotype is associated with stem-like abilities, such as increased ability to selfrenew and to form tumours in immunodeficient mice. Although it remains to be validated whether Aldefluor and CD133 in combination can be used to isolate CSCs from liposarcomas and sarcomas in general, these markers have proven useful for isolating CSCs across tumor types [13], and may be used as targets for novel CSC-specific therapies. Ongoing work includes specifically targeting and killing the CSC population in our model system.

\section{List of abbreviations}

CSC: cancer stem cell; bFGF: basic fibroblast growth factor; FGFR: fibroblast growth factor receptor; HSC: hematopoietic stem cell; MSC: mesenchymal stem cell; ALDH: aldehyde dehydrogenase. 


\section{Acknowledgements}

We thank Alexandr Kristian, Hege Christin Svensson, Petros Gebregziabher and Mette Førsund for technical assistance with the tumourigenicity assays and immunohistochemical analysis. The work was supported by a grant from the Norwegian Research Council.

\section{Author details}

${ }^{1}$ Cancer Stem Cell Innovation Centre and Department of Tumor Biology, Institute of Cancer Research, Oslo University Hospital, The Norwegian Radium Hospital, PO Box 4953 Nydalen, Oslo, NO-0424, Norway. 2Department of Pathology, Oslo University Hospital, The Norwegian Radium Hospital, PO Box 4953 Nydalen, Oslo, NO-0424, Norway. ${ }^{3}$ Department of Molecular Bioscience, University of Oslo, PO-Box 1041 Blindern, Oslo, NO0316, Norway.

\section{Authors' contributions}

EWS, EM and OM designed the study and wrote the manuscript. EWS, ABW and SL performed the practical work, apart from the flow cytometry which was done by $\mathrm{RC}$ and the immunohistochemistry performed by $\mathrm{RH}$. $\mathrm{RH}$ and BB performed pathological analyses. All authors read and approved the final manuscript.

\section{Competing interests}

The authors declare that they have no competing interests.

Received: 5 April 2011 Accepted: 1 August 2011

Published: 1 August 2011

\section{References}

1. Vermeulen L, Sprick MR, Kemper K, Stassi G, Medema JP: Cancer stem cells - old concepts, new insights. Cell Death Differ 2008, 15:947-958.

2. Bomken S, Fiser $\mathrm{K}$, Heidenreich $\mathrm{O}$, Vormoor J: Understanding the cancer stem cell. Br J Cancer 103:439-445.

3. Kondo T: Stem cell-like cancer cells in cancer cell lines. Cancer Biomark 2007, 3:245-250.

4. Colvin M, Russo JE, Hilton J, Dulik DM, Fenselau C: Enzymatic mechanisms of resistance to alkylating agents in tumor cells and normal tissues. Adv Enzyme Regul 1988, 27:211-221.

5. Russo JE, Hilton J, Colvin OM: The role of aldehyde dehydrogenase isozymes in cellular resistance to the alkylating agent cyclophosphamide. Prog Clin Biol Res 1989, 290:65-79.

6. Chute JP, Muramoto GG, Whitesides J, Colvin M, Safi R, et al: Inhibition of aldehyde dehydrogenase and retinoid signaling induces the expansion of human hematopoietic stem cells. Proc Natl Acad Sci USA 2006, 103:11707-11712.

7. Douville J, Beaulieu R, Balicki D: ALDH1 as a functional marker of cancer stem and progenitor cells. Stem Cells Dev 2009, 18:17-25.

8. Ginestier C, Hur MH, Charafe-Jauffret E, Monville F, Dutcher J, et al: ALDH1 is a marker of normal and malignant human mammary stem cells and a predictor of poor clinical outcome. Cell Stem Cell 2007, 1:555-567.

9. Ran D, Schubert M, Pietsch L, Taubert I, Wuchter P, et al: Aldehyde dehydrogenase activity among primary leukemia cells is associated with stem cell features and correlates with adverse clinical outcomes. Exp Hematol 2009, 37:1423-1434.

10. Li T, Su Y, Mei $Y$, Leng $Q$, Leng $B$, et al: ALDH1A1 is a marker for malignant prostate stem cells and predictor of prostate cancer patients' outcome. Lab Invest 90:234-244.

11. Huang EH, Hynes MJ, Zhang T, Ginestier C, Dontu G, et al: Aldehyde dehydrogenase 1 is a marker for normal and malignant human colonic stem cells (SC) and tracks SC overpopulation during colon tumorigenesis. Cancer Res 2009, 69:3382-3389.

12. Su Y, Qiu Q, Zhang X, Jiang Z, Leng Q, et al: Aldehyde dehydrogenase 1 A1-positive cell population is enriched in tumor-initiating cells and associated with progression of bladder cancer. Cancer Epidemiol Biomarkers Prev 19:327-337.

13. Ma S, Chan KW, Lee TK, Tang KH, Wo JY, et al: Aldehyde dehydrogenase discriminates the CD133 liver cancer stem cell populations. Mol Cancer Res 2008, 6:1146-1153.

14. Yokota A, Takeuchi H, Maeda N, Ohoka Y, Kato C, et al: GM-CSF and IL-4 synergistically trigger dendritic cells to acquire retinoic acid-producing capacity. Int Immunol 2009, 21:361-377.
15. Wang L, Park P, Zhang H, La Marca F, Lin CY: Prospective identification of tumorigenic osteosarcoma cancer stem cells in OS99-1 cells based on high aldehyde dehydrogenase activity. Int J Cancer 128:294-303.

16. Jiang F, Qiu Q, Khanna A, Todd NW, Deepak J, et al: Aldehyde dehydrogenase 1 is a tumor stem cell-associated marker in lung cancer. Mol Cancer Res 2009, 7:330-338.

17. Deng S, Yang $X$, Lassus H, Liang S, Kaur S, et al: Distinct expression levels and patterns of stem cell marker, aldehyde dehydrogenase isoform 1 (ALDH1), in human epithelial cancers. PLoS One 5:e10277.

18. Charafe-Jauffret E, Ginestier C, lovino F, Tarpin C, Diebel M, et al: Aldehyde dehydrogenase 1-positive cancer stem cells mediate metastasis and poor clinical outcome in inflammatory breast cancer. Clin Cancer Res 16:45-55.

19. Chen YC, Chen YW, Hsu HS, Tseng LM, Huang Pl, et al: Aldehyde dehydrogenase 1 is a putative marker for cancer stem cells in head and neck squamous cancer. Biochem Biophys Res Commun 2009, 385:307-313.

20. Tanei T, Morimoto K, Shimazu K, Kim SJ, Tanji Y, et al: Association of breast cancer stem cells identified by aldehyde dehydrogenase 1 expression with resistance to sequential Paclitaxel and epirubicin-based chemotherapy for breast cancers. Clin Cancer Res 2009, 15:4234-4241.

21. Yin AH, Miraglia S, Zanjani ED, Almeida-Porada G, Ogawa M, et al: AC133, a novel marker for human hematopoietic stem and progenitor cells. Blood 1997, 90:5002-5012.

22. Wu Y, Wu PY: CD133 as a marker for cancer stem cells: progresses and concerns. Stem Cells Dev 2009, 18:1127-1134.

23. Singh SK, Clarke ID, Terasaki M, Bonn VE, Hawkins C, et al: Identification of a cancer stem cell in human brain tumors. Cancer Res 2003, 63:5821-5828.

24. Singh SK, Hawkins C, Clarke ID, Squire JA, Bayani J, et al: Identification of human brain tumour initiating cells. Nature 2004, 432:396-401.

25. O'Brien CA, Pollett A, Gallinger S, Dick JE: A human colon cancer cell capable of initiating tumour growth in immunodeficient mice. Nature 2007, 445:106-110.

26. Ricci-Vitiani L, Lombardi DG, Pilozzi E, Biffoni M, Todaro $M$, et al: Identification and expansion of human colon-cancer-initiating cells. Nature 2007, 445:111-115.

27. Hermann PC, Huber SL, Herrler T, Aicher A, Ellwart JW, et al: Distinct populations of cancer stem cells determine tumor growth and metastatic activity in human pancreatic cancer. Cell Stem Cell 2007, 1:313-323.

28. Ma S, Chan KW, Hu L, Lee TK, Wo JY, et al: Identification and characterization of tumorigenic liver cancer stem/progenitor cells. Gastroenterology 2007, 132:2542-2556.

29. Tirino V, Desiderio V, Paino F, De Rosa A, Papaccio F, et al: Human primary bone sarcomas contain CD133+ cancer stem cells displaying high tumorigenicity in vivo. Faseb J 25:2022-2030.

30. Jiang X, Gwye Y, Russell D, Cao C, Douglas D, et al: CD133 expression in chemo-resistant Ewing sarcoma cells. BMC Cancer 10:116.

31. Suva ML, Riggi N, Stehle JC, Baumer K, Tercier S, et al: Identification of cancer stem cells in Ewing's sarcoma. Cancer Res 2009, 69:1776-1781.

32. Terry J, Nielsen T: Expression of CD133 in synovial sarcoma. Appl Immunohistochem Mol Morphol 18:159-165.

33. Tirino $V$, Desiderio $V$, d'Aquino $R$, De Francesco F, Pirozzi G, et al: Detection and characterization of CD133+ cancer stem cells in human solid tumors. PLoS One 2008, 3:e3469.

34. Al-Hajj M, Wicha MS, Benito-Hernandez A, Morrison SJ, Clarke MF: Prospective identification of tumorigenic breast cancer cells. Proc Natl Acad Sci USA 2003, 100:3983-3988.

35. Amit M, Carpenter MK, Inokuma MS, Chiu CP, Harris CP, et al: Clonally derived human embryonic stem cell lines maintain pluripotency and proliferative potential for prolonged periods of culture. Dev Biol 2000, 227:271-278.

36. Lee J, Kotliarova S, Kotliarov Y, Li A, Su Q, et al: Tumor stem cells derived from glioblastomas cultured in bFGF and EGF more closely mirror the phenotype and genotype of primary tumors than do serum-cultured cell lines. Cancer Cell 2006, 9:391-403.

37. Ponti D, Costa A, Zaffaroni N, Pratesi G, Petrangolini G, et al: Isolation and in vitro propagation of tumorigenic breast cancer cells with stem/ progenitor cell properties. Cancer Res 2005, 65:5506-5511.

38. Villegas SN, Canham M, Brickman JM: FGF signalling as a mediator of lineage transitions-evidence from embryonic stem cell differentiation. J Cell Biochem 110:10-20. 
39. Chamberlain G, Fox J, Ashton B, Middleton J: Concise review: mesenchymal stem cells: their phenotype, differentiation capacity, immunological features, and potential for homing. Stem Cells 2007, 25:2739-2749.

40. Park PC, Selvarajah S, Bayani J, Zielenska M, Squire JA: Stem cell enrichment approaches. Semin Cancer Biol 2007, 17:257-264.

41. Bidlingmaier S, Zhu X, Liu B: The utility and limitations of glycosylated human CD133 epitopes in defining cancer stem cells. J Mol Med 2008, 86:1025-1032.

42. Keysar SB, Jimeno A: More than markers: biological significance of cancer stem cell-defining molecules. Mol Cancer Ther 9:2450-2457.

43. Todaro M, Alea MP, Di Stefano AB, Cammareri P, Vermeulen L, et al: Colon cancer stem cells dictate tumor growth and resist cell death by production of interleukin-4. Cell Stem Cell 2007, 1:389-402.

44. Mizrak D, Brittan M, Alison MR: CD133: molecule of the moment. J Pathol 2008, 214:3-9.

45. Kemper K, Sprick MR, de Bree M, Scopelliti A, Vermeulen L, et al: The AC133 epitope, but not the CD133 protein, is lost upon cancer stem cell differentiation. Cancer Res 70:719-729.

doi:10.1186/2045-3329-1-8

Cite this article as: Stratford et al:: Liposarcoma cells with aldefluor and CD133 activity have a cancer stem cell potential. Clinical Sarcoma Research 2011 1:8.

\section{Submit your next manuscript to BioMed Central} and take full advantage of:

- Convenient online submission

- Thorough peer review

- No space constraints or color figure charges

- Immediate publication on acceptance

- Inclusion in PubMed, CAS, Scopus and Google Scholar

- Research which is freely available for redistribution

Submit your manuscript at www.biomedcentral.com/submit 